\begin{tabular}{ccc|} 
ISSN = 1980-993X - doi:10.4136/1980-993X \\
www.agro.unitau.br/ambi-agua \\
E-mail: ambi-agua@agro.unitau.br \\
Tel.: (12) 3625-4116
\end{tabular}

\title{
Diagnóstico hidroambiental da bacia hidrográfica da Cachoeira das Pombas, município de Guanhães, MG, Brasil
}

(doi:10.4136/ambi-agua.80)

\author{
Kelly Cristina Tonello ${ }^{1}$; Herly Carlos Teixeira Dias ${ }^{2}$; Agostinho Lopes de Souza $^{2}$; Carlos \\ Antonio Alvares Soares Ribeiroº ${ }^{2}$ Deuseles João Firme ${ }^{3}$; Fernando Palha Leite ${ }^{3}$ \\ ${ }^{1}$ Dep. de Engenharia Florestal, UFSCar, SP 264, Km 110, CEP 18.052-780, Sorocaba-SP \\ E-mail: kellytonello@ufscar.br \\ 2Dep. Engenharia Florestal, UFV, 36571-000 Viçosa-MG \\ E-mail: herly@ufv.br \\ ${ }^{3}$ Celulose Nipo-Brasileira S.A - CENIBRA, Ipatinga-MG \\ E-mail: \{deuseles.firme, fernando.leite\}@cenibra.com.br
}

\section{RESUMO}

O objetivo deste trabalho foi avaliar o estado de conservação hídrica e ambiental da bacia hidrográfica da Cachoeira das Pombas, localizada no município de Guanhães-MG, visando a seu manejo integrado. A caracterização das nascentes foi realizada quanto ao seu tipo, persistência de fluxo, estado de conservação, valores de vazão e avaliação do estado de conservação hídrico e ambiental. Para uma análise mais detalhada, a bacia hidrográfica foi dividida em sub-bacias. De forma geral, quanto ao estado de conservação hídrico e ambiental da bacia hidrográfica, conclui-se pela necessidade de se realizar práticas de manejo integrado dos recursos naturais, uma vez que a vazão dos cursos d'água apresentou-se desregularizada, com grandes oscilações entre as estações chuvosa e seca, além da presença de vários focos de erosão e assoreamentos, no período estudado.

Palavras-chave: hidrologia florestal; manejo de bacias hidrográficas; nascentes; Eucalyptus sp.

\section{Hydrological and environmental diagnostic of the Cachoeira das Pombas's watershed, Guanhães, MG, Brazil}

\begin{abstract}
The objective of this work was to evaluate hydrological and environmental issues of Cachoeira das Pombas watershed, in Guanhães, eastern Minas Gerais State, Brazil, to support its management plan. The characterization of water springs included the definition of its types, assessment of flow persistence, conservation state, outflow values, and the hydrological and environmental conservation state of the watershed. For a detailed analysis, the watershed was studied considering each of its small watersheds. Analyzing the hydrological and environmental conservation state of the watershed, it was concluded that an integrated management of natural resources is necessary inasmuch as the flow rate showed to be irregular, with great variation between the rainy and dry seasons and several erosion and silting spots observed during the study period.
\end{abstract}

Keywords: forest hydrology; watershed management; springs; Eucalyptus sp. 


\section{INTRODUÇÃO}

A utilização da bacia hidrográfica como unidade de planejamento e gerenciamento ambiental não é recente. Há tempos os hidrólogos têm reconhecido as ligações entre características físicas de uma bacia hidrográfica e a quantidade de água que chega aos corpos hídricos. Por outro lado, os limnólogos têm considerado que as características do corpo d'água refletem as características de sua bacia de drenagem. Nesse sentido, as abordagens de planejamento e gerenciamento ambiental utilizando a bacia hidrográfica como unidade de estudo têm evoluído bastante, desde que estas apresentam características biogeofísicas que denominam sistemas ecológicos e hidrológicos relativamente coesos (Pires et al., 2002).

Para o trabalho de conservação do solo e da água, algumas regiões utilizavam como unidades de planejamento, a propriedade e a comunidade. No entanto, esses limites, via de regra, não coincidem com os limites naturais. O planejamento ambiental por bacia hidrográfica, por outro lado, apresenta a vantagem de concentrar as ações numa área geográfica definida previamente com o auxílio de cartas topográficas e delimitada pelos divisores de água, de onde fluem as águas da chuva para as partes mais baixas do terreno, formando os cursos d'água. Nas bacias estão localizadas as nascentes dos córregos, que compõem, junto com os rios dos quais são tributários, o sistema de drenagem de uma determinada região. Assim, as intervenções no nível da sub-bacia visam atenuar os impactos gerados pela ação humana nas cabeceiras dos rios, como forma de beneficiar tanto a população da área rural, quanto às populações das cidades, geralmente localizadas a jusante das bacias (Farah e Barboza, 2000).

O estudo e a compreensão da distribuição da água na vegetação, principalmente a florestal, podem gerar formas de manejo tecnicamente viáveis, facilitando a tomada de decisões importantes para o uso integrado das bacias hidrográficas (Valcarcel, 1984).

Durante a Conferência IUFRO sobre Silvicultura e Melhoramento de Eucaliptos, Lima (1997) discorreu sobre a polêmica das plantações florestais com espécies de rápido crescimento, principalmente com eucaliptos, criticadas por seus impactos ambientais. De acordo com o autor, as evidências disponíveis são claras para eliminar a maior parte das afirmações exageradas nesta polêmica, mas de qualquer forma, há bastante espaço para a melhoria das práticas de manejo das plantações florestais visando minimizar efeitos ecológicos, a fim de garantir a integridade do ecossistema. A noção da microbacia hidrográfica como unidade ecossistêmica de planejamento das atividades florestais, possibilita a identificação de indicadores hidrológicos para o manejo sustentável de recursos naturais.

É notório que a irregularidade da distribuição temporal das chuvas tem sido a responsável pela insatisfação dos consumos da população em épocas de estiagem. Contudo, a degradação ambiental dos recursos naturais de uma bacia hidrográfica pode comprometer as reservas subterrâneas, aumentando ainda mais essas dificuldades. Desse modo, torna-se necessário conhecer em profundidade o funcionamento dos ecossistemas e os fatores que atuam sobre eles, a fim de obter referenciais que permitam a avaliação da magnitude dos impactos ambientais decorrentes da intervenção antrópica sobre eles..

Diante do exposto, o objetivo deste estudo foi analisar o estado de conservação hídrica e ambiental da bacia hidrográfica da Cachoeira das Pombas, localizada no município de Guanhães-MG. 


\section{MATERIAL E MÉTODOS}

\subsection{Localização}

O presente estudo foi realizado em área de propriedade da empresa Celulose NipoBrasileira - CENIBRA S.A., nos limites do projeto Cachoeira das Pombas, município de Guanhães - MG, região do Alto e Médio rio Doce.

A bacia hidrográfica da Cachoeira das Pombas pertence à bacia do rio Corrente Grande, afluente à margem esquerda do rio Doce e drena parcialmente a região onde se inserem os municípios de Guanhães, Virginópolis, São João Evangelista, Gonzaga, Santa Efigênia de Minas, São Geraldo da Piedade, Açucena, Periquito, Governador Valadares e Divinolândia de Minas (Figura 1).

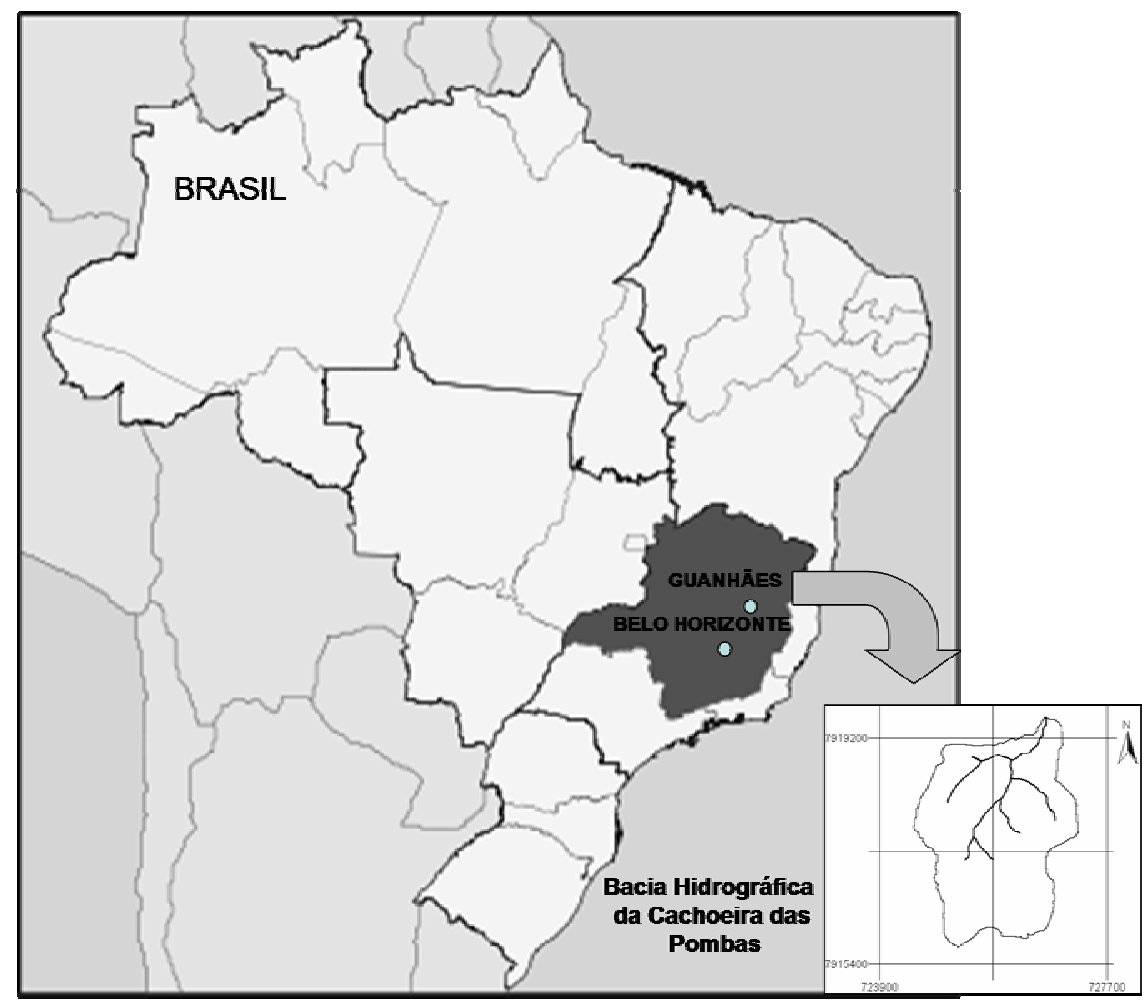

Figura 1. Localização da bacia hidrográfica da Cachoeira das Pombas, Guanhães-MG.

\subsection{Clima}

Segundo a classificação climática de Köppen, o clima predominante na região é Aw Clima Tropical chuvoso de savana, ou seja, inverno seco e chuvas máximas no verão. Conforme a classificação climática de Thornthwaite, o clima de Guanhães é $\mathrm{C}_{2} \mathrm{rB}^{`}{ }_{4} \mathrm{a}$ `, isto é, clima subúmido, com deficiência de água pequena ou nula, mesotérmico (Souza et al., 2006). De acordo com os dados registrados pela estação meteorológica da CENIBRA em Guanhães, para o período de 1985 a 2004, o município apresenta uma estação seca bem definida, de junho a agosto, correspondendo a 2,8\% do total anual precipitado. Esse período coincide ainda com o período de inverno, quando se observam as menores temperaturas. Os meses com maiores ocorrências de chuva correspondem ao período de outubro a março, sendo denominado de "estação chuvosa". Nesse período, observa-se o total precipitado de $87 \%$ do total anual. O balanço hídrico para o período de 1985 a 2004 (Figura 2) apresenta precipitação anual de $1179 \mathrm{~mm}$ e a temperatura média de $21,8^{\circ} \mathrm{C}$. 


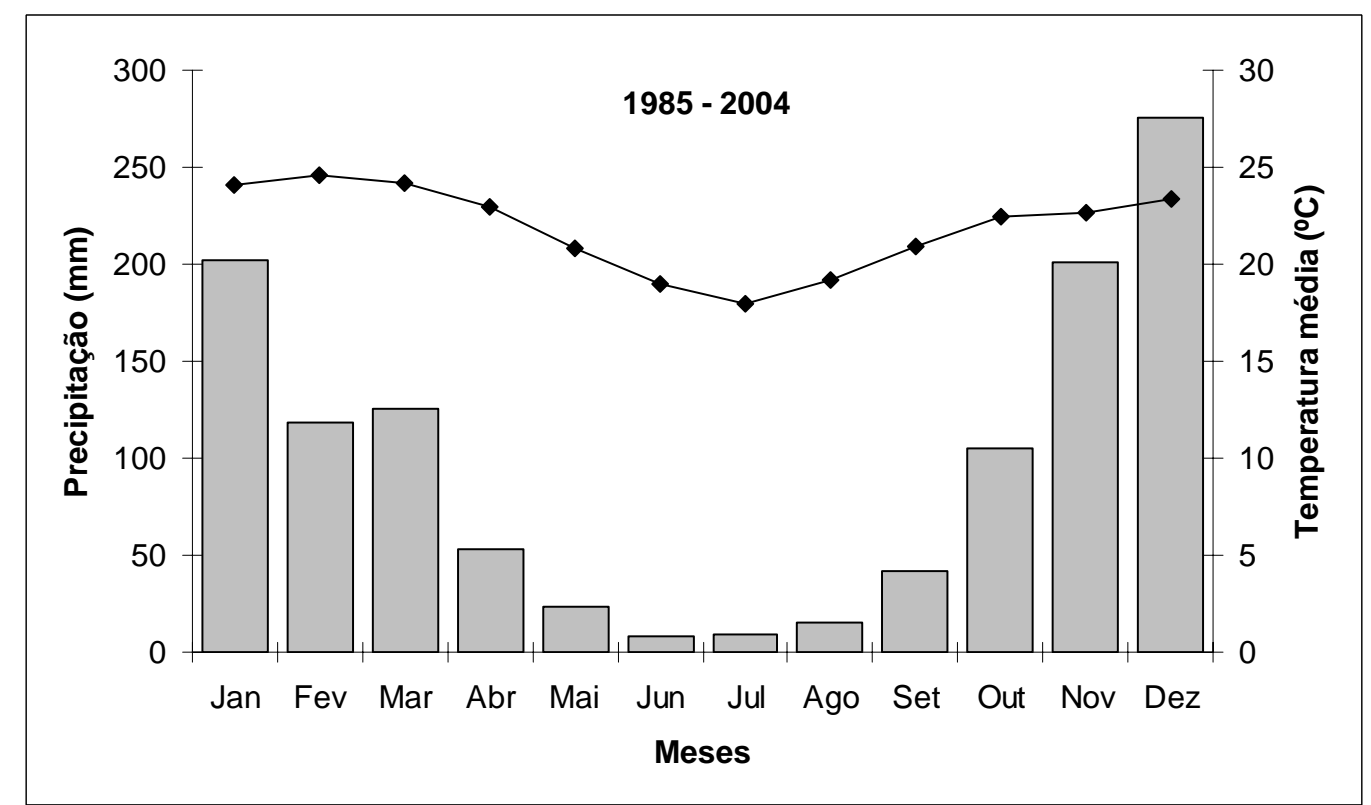

Figura 2. Precipitação total e temperatura média mensal para o município de Guanhães-MG, média para o período de 1985 e 2004.

\subsection{Morfometria da bacia hidrográfica}

De acordo com Tonello et al (2006), a bacia hidrográfica da Cachoeira das Pombas possui área de drenagem pequena (698,1 ha), altitude média igual a $921 \mathrm{~m}$, alta declividade (34\% - relevo forte ondulado) e forma alongada (fator de forma, coeficiente de compacidade e índice de circularidade iguais a 0,4, 1,6 e 0,4, respectivamente). A densidade de drenagem $\left(\mathrm{Dd}=1,0 \mathrm{~km} / \mathrm{km}^{2}\right)$ é baixa e grande porcentagem do terreno da bacia em estudo possui exposição do terreno para a face Norte - Oeste (aproximadamente $41 \%$ ), indicando deficiência na retenção de umidade.

As cinco sub-bacias são morfometricamente distintas. As sub-bacias 2, 3, 4 e 5 apresentam maior declividade do que a sub-bacia 1; as sub-bacias 1, 2 e 3 com áreas maiores e semelhantes e as sub-bacias 4 e 5 com áreas menores e também semelhantes, muito embora a forma das sub-bacias seja aproximadamente igual.

\subsection{Características geológicas e uso atual do solo}

A área de influência da CENIBRA S.A. está inserida em uma grande unidade geológica caracterizada por rochas proterozóicas, que ocupa grande extensão da bacia do Rio Doce. Localmente há ocorrência de granitos e itabiritos (Burla, 2001) e rochas magnesíferas, metabasaltos, anfibolitos, xistos e cataitabiritos (CENIBRA, 2003).

De acordo com Burla (2001), os solos da área de estudo possuem profundidade média à alta, fertilidade baixa, com alta acidez, textura argilosa à muito argilosa, e média vulnerabilidade quanto à erosão, compactação e presença de cascalho. A classificação dos solos nas áreas de plantio de eucalipto podem ser visualizadas na Figura 2. A classe de solo citada inicialmente é o predominante em cada talhão.

O histórico da área de estudo consta que, antes da aquisição da propriedade pela Florestas Rio Doce S.A. para plantio de eucalipto em 1972, toda a bacia era ocupada com vegetação nativa. Em 1984, a CENIBRA adquiriu a área, mantendo a mesma atividade econômica.

Desde o início do plantio de eucalipto na área (1972), a distribuição espacial do uso do solo (áreas de reserva legal, preservação permanente, plantios de eucalipto e represas) não 
sofreu mudanças significativas, sendo mínimos os impactos ambientais da atividade florestal sobre os remanescentes florestais nativos.

Cerca de 350 ha da bacia possui plantios efetivos de Eucalyptus grandis, em espaçamento $3 \times 2 \mathrm{~m}$, distribuídos em talhões reformados (auto-fuste) e regenerados (talhadia), com idade entre 8 e 11 anos. A limpeza anterior da área foi realizada com o uso de fogo e o preparo do solo, por coveamento manual $(20$ x 20 × $25 \mathrm{~cm})$.

\subsection{Características Biológicas}

A cobertura vegetal original onde se insere a área de estudo, a leste do Estado de Minas Gerais, está situada nos limites da Floresta Atlântica (Fundação S.O.S Mata Atlântica/ Instituto Nacional de Pesquisas Espaciais/ Instituto Sócio-Ambiental, 1998). Entretanto, devido à proximidade com o cerrado, a cobertura florestal dessa região sofre interferências desse ecossistema, evidenciado pela existência de diversas espécies típicas desse tipo de ambiente como Byrsonima sp., Cordia sellowiana, Machaerium villosum, Machaerium opacum, dentre outras (CENIBRA, 2003).

O Mapa de Vegetação do Brasil (Instituto Brasileiro de Geografia e Estatística, 1993), coloca as formações florestais de ocorrência natural da região como pertencentes à Região Ecológica da Floresta Estacional Semidecidual (Mata Semicaducifólia), assinalando que nessa região florestal são dominantes os gêneros neotropicais Tabebuia, Paratecoma, Cariniana, entre outros, em mistura com os gêneros paleotropicais Terminalia e Erithrina, e com gêneros austrálicos Cedrela e Sterculia (CENIBRA, 2003).

Na região de estudo, encontraram-se ainda, quatro espécies citadas na Lista de Espécies da Flora Ameaçada de Extinção publicada pelo IBAMA: Braúna (Melanoxylon brauna), Jacarandá-da-bahia (Dalbergia nigra), Gonçalo-alves (Astronium fraxinifolium) e Peroba-rosa (Aspidosperma polyneuron).

O uso do solo citado permitiu a regeneração de vegetação arbórea nativa, nas áreas preservadas, sendo que, segundo CENIBRA (2003), 38\% da área encontram-se nos estágios de sucessão secundária inicial e 51\%, em estágio médio de sucessão secundária. Os 11\% restantes compreendem áreas com afloramentos rochosos e vegetação rupestre, caracterizados pela ocorrência de solos rasos, ilhados pela vegetação arbórea, permitindo a ocorrência de ambientes rupestres, com árvores baixas e retorcidas e espécies das famílias Cyperaceae, Bromeliaceae, Gramineae e Orchidaceae.

\subsection{Caracterização das nascentes e diagnóstico hidroambiental}

Toda a bacia hidrográfica foi percorrida para um reconhecimento in loco de seus detalhes a respeito do uso do solo e conservação da bacia, assim como para a realização de medições de vazão das nascentes.

As nascentes foram caracterizadas quanto ao seu tipo e persistência, em que se avaliou também o seu estado de conservação, sendo classificadas como preservadas (quando da presença de vegetação nativa em um raio maior ou igual a $50 \mathrm{~m}$ ), perturbadas (quando não apresentam 50 metros de vegetação nativa no seu entorno, mas se encontram em bom estado de conservação) e degradada (presença de eucalipto no entorno, estradas, erosões e assoreamentos). Metodologia semelhante foi realizada por Pinto et al. (2004), Matteucci et al. (2007), Santana et al. (2007).

As aferições hidrológicas foram realizadas no mês de outubro de 2004, antecedendo o início das chuvas, representando, portanto, a vazão mínima das nascentes na bacia hidrográfica (fim da estação seca) e em janeiro de 2005, mês intermediário de estação chuvosa. As vazões foram obtidas por meio de método indireto, pelo uso de micromolinete 
modelo FP201 - Global Flow Probe. Quando da impossibilidade desse instrumento, trabalhou-se com o método direto, aplicável nos casos de pequenas vazões. Esse processo consistiu em três medições diretas do volume de água contido em um recipiente de 20 litros, armazenado em 10 segundos contabilizados com auxílio de um cronômetro digital. A vazão das nascentes foi obtida pela equação:

$$
\bar{Q}=\frac{\sum\left(\frac{V}{t}\right)}{3}
$$

em que,

$\bar{Q}=$ vazão média $(\mathrm{l} / \mathrm{s})$

$\mathrm{t}=$ tempo, em segundos

$\mathrm{V}=$ volume de água, em litros

\section{RESULTADOS E DISCUSSÃO}

Ao percorrer a área de estudo, foram identificadas três nascentes perenes, três nascentes intermitentes e cinco represas (Figura 3).

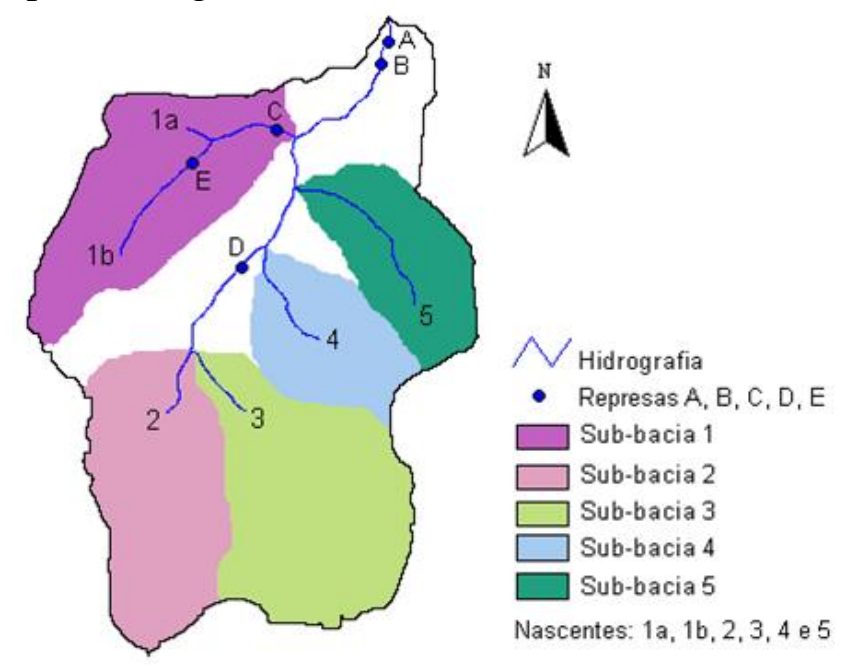

Figura 3. Delimitação das sub-bacias, nascentes e represas, Cachoeira das Pombas, Guanhães, MG, 2004.

Apesar das áreas de plantio possuírem seu sub-bosque protegido com a própria serapilheira, foram constatadas algumas falhas relacionadas à conservação de solo e água.

As nascentes 2 e 3 possuem vazão durante todo o ano e encontram-se preservadas, ao passo que a nascente 4, embora perene, apresentou-se perturbada (Tabela 1). As demais nascentes são caracterizadas como intermitentes e variam quanto ao tipo e estado de conservação. 
TONELLO, K. C.; DIAS, H. C. T.; SOUZA, A. L.; RIBEIRO, C. A. A. S.; FIRME, D. J.; LEITE, F. P. Diagnóstico hidroambiental da bacia hidrográfica da Cachoeira das Pombas, município de Guanhães, MG, Brasil. Ambi-Agua, Taubaté, v. 4, n. 1, p. 156-168, 2009. (doi:10.4136/ambi-agua.80)

Tabela 1. Caracterização das nascentes, Cachoeira das Pombas, Guanhães, MG, 2004.

\begin{tabular}{clllcc}
\hline Nascente & Persistência & Tipo & Vegetação & $\begin{array}{c}\text { Q estação seca } \\
\text { (l/s) }\end{array}$ & $\begin{array}{c}\text { Q estação } \\
\text { chuvosa (l/s) }\end{array}$ \\
\hline 1 a & Intermitente & Difusa & Degradada & - & - \\
1 b & Intermitente & Encosta & Preservada & 0,00 & 0,53 \\
2 & Perene & Encosta & Preservada & 0,19 & 1,01 \\
3 & Perene & Encosta & Preservada & 0,06 & 0,78 \\
4 & Perene & Encosta & Perturbada & 0,12 & 0,59 \\
5 & Intermitente & Encosta & Degradada & 0,00 & 0,08 \\
\hline
\end{tabular}

A represa D (Figura 4) recebe a água das nascentes 2 e 3. Por meio de um diagnóstico visual, observou-se um aspecto amarelado (barrento) da água, indicando a ocorrência de perda de solos, nutrientes e matéria orgânica nas áreas a montante da represa, ao contrário do que pôde ser observado durante a época de estiagem.

Para Mosca (2003), os indicadores visuais expressam o resultado das ações humanas ao longo do tempo, facilmente percebidas na paisagem. Ainda de acordo com o mesmo autor, como os parâmetros da qualidade da água, os atributos visualmente percebidos na paisagem permitem integrar respostas às práticas de manejo na escala de microbacia.

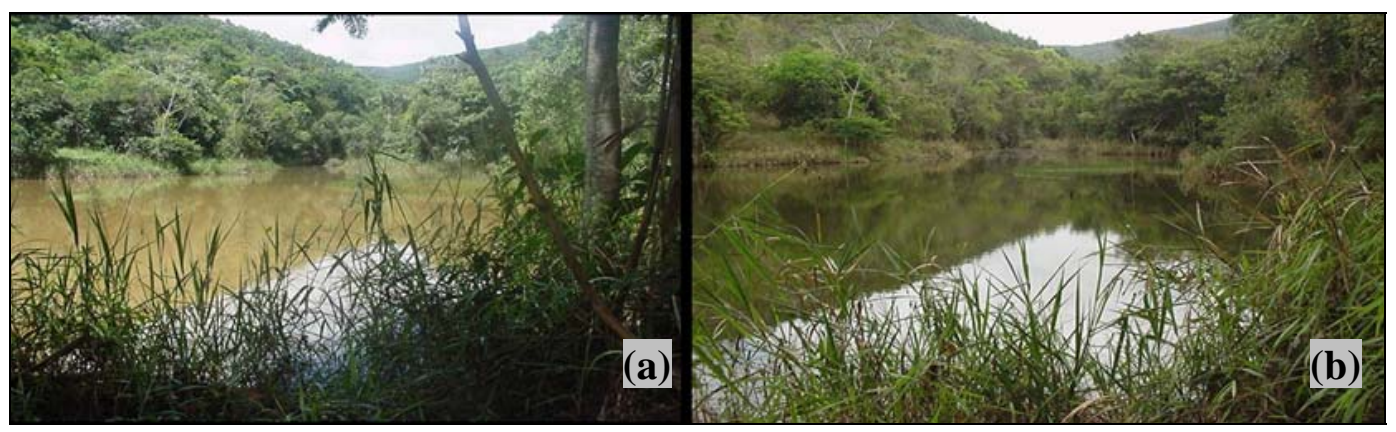

Figura 4. Visualização da represa D, bacia hidrográfica da Cachoeira das Pombas, Guanhães, MG, 2004. (a) estação chuvosa e (b) estação de estiagem.

A Figura 5 apresenta um panorama da área de contribuição da sub-bacia 1, onde estão inseridas as nascentes 1a e 1b. No divisor de águas dessa sub-bacia, foi possível identificar a presença de plantios de eucalipto e uma forte presença de rochas, muitas vezes expostas, formando um vale onde é notável a presença de floresta nativa. A variação de vazão da nascente $1 \mathrm{~b}$ entre outubro e janeiro pode estar relacionada ao afloramento de rochas como o granito, vindo a escoar superficialmente toda a água precipitada, contribuindo para as altas vazões no período chuvoso. Esse fato pode ser comprovado pela Figura 6, a qual ilustra a represa E que armazena a vazão da nascente $1 \mathrm{~b}$ nas estações de chuva e seca, respectivamente.

De acordo com Lima et al. (2002), o traçado inadequado de estradas e carreadores afeta o funcionamento hidrológico de toda a bacia. Os problemas mais graves causados pela má locação da rede viária estão associados à captação, à condução e ao deságüe concentrado de enxurrada em determinados pontos do terreno, ocasionando erosão laminar e, ou em sulcos na própria estrada e em talhões adjacentes. Além da queda de produtividade ocasionada pela erosão, o assoreamento de cursos d'água e a perda de valores estéticos e paisagísticos são danos possíveis da má locação e manutenção viária (Gonçalves, 2002), revestindo-se de 
TONELLO, K. C.; DIAS, H. C. T.; SOUZA, A. L.; RIBEIRO, C. A. A. S.; FIRME, D. J.; LEITE, F. P. Diagnóstico hidroambiental da bacia hidrográfica da Cachoeira das Pombas, município de Guanhães, MG, Brasil. Ambi-Agua, Taubaté, v. 4, n. 1, p. 156-168, 2009. (doi:10.4136/ambi-agua.80)

grande importância a captação e o disciplinamento dessas águas, de forma a eliminar seu efeito destruidor. Isso pode ser realizado acumulando-as em locais determinados e forçando sua penetração no solo, favorecendo o abastecimento do lençol freático e, consequentemente, alimentando as fontes e nascentes naturais. Ao percorrer as áreas de contribuição das subbacias, essa situação foi visualizada em vários pontos.

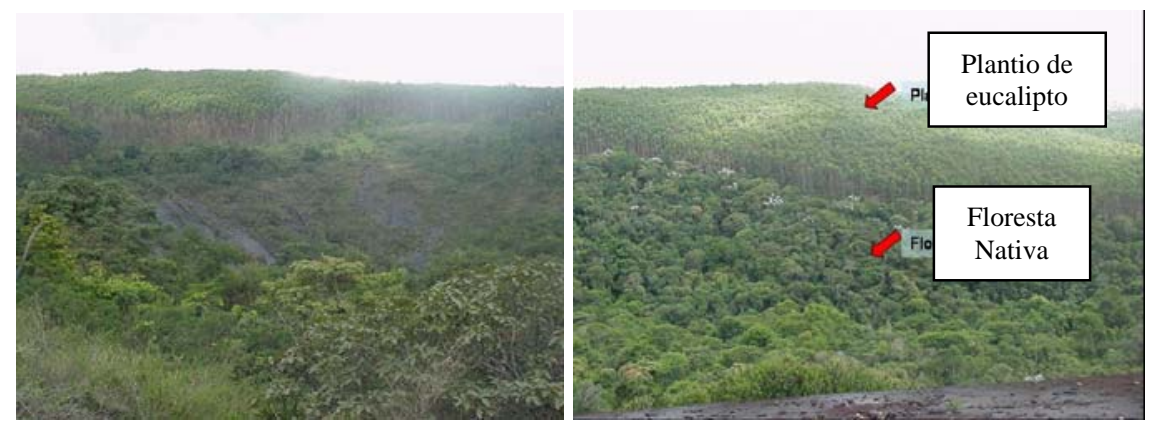

Figura 5. Área de contribuição da nascente 1b, Cachoeira das Pombas, Guanhães-MG, 2004.
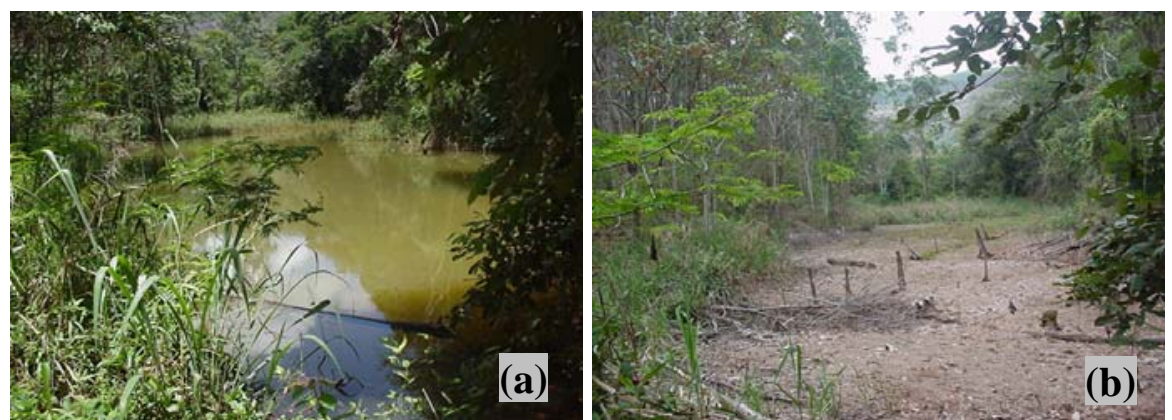

Figura 6. Represa E que armazena água da nascente 1b, Cachoeira das Pombas, Guanhães, MG, 2004: (a) estação chuvosa e (b) estação seca.

O diagnóstico realizado na nascente $1^{\mathrm{a}}$ constatou que ela possui vazão somente na estação de chuva, é do tipo difusa e caracterizada como degradada, uma vez que a estrada de contorno sobrepõe parte de sua zona ripária. Esse fato, aliado à presença de rochas impermeáveis nessa sub-bacia, acarreta a diminuição de infiltração de água no solo, impedindo o abastecimento do lençol subterrâneo.

A nascente 5, caracterizada como intermitente e degradada, está localizada a 20 metros da estrada, com remanescentes de eucalipto dentro do raio de 50 metros, apresentando em grande parte do curso d'água, a deposição de sedimentos e permanecendo, até mesmo na estiagem, assoreada (Figuras 7 e 8).
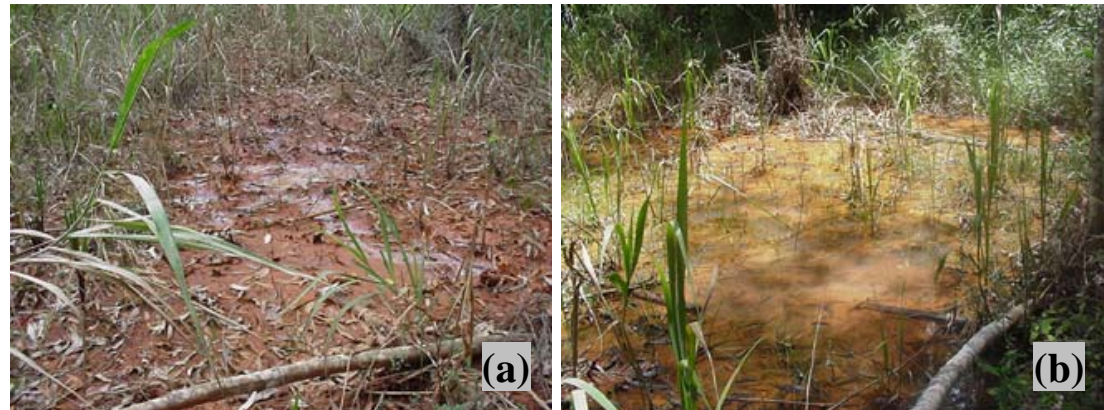

Figura 7. Nascente 5, Cachoeira das Pombas, Guanhães, MG, 2004: (a) estação chuvosa e (b) estação seca. 
TONELlO, K. C.; DIAS, H. C. T.; SOUZA, A. L.; RIBEIRO, C. A. A. S.; FIRME, D. J.; LEITE, F. P. Diagnóstico hidroambiental da bacia hidrográfica da Cachoeira das Pombas, município de Guanhães, MG, Brasil. Ambi-Agua, Taubaté, v. 4, n. 1, p. 156-168, 2009. (doi:10.4136/ambi-agua.80)
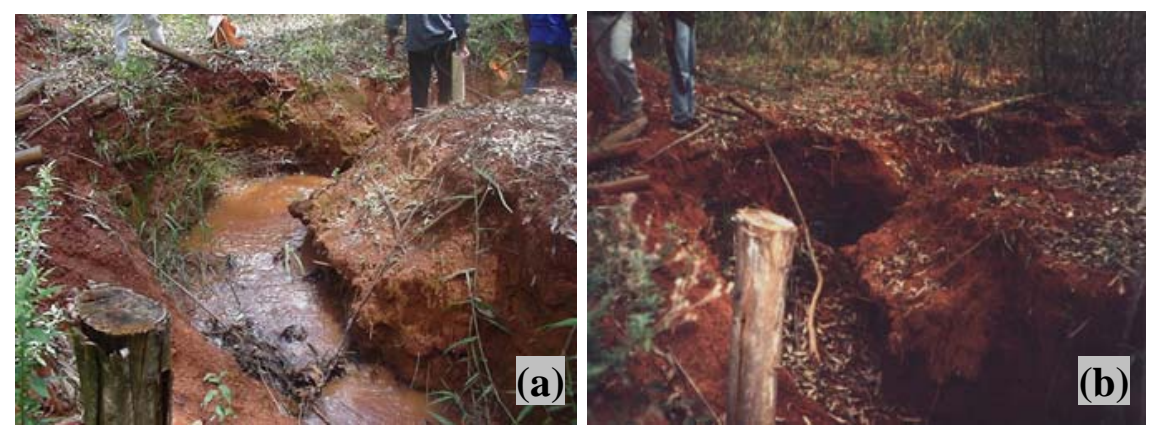

Figura 8. Curso d’água da nascente 5, Cachoeira das Pombas, Guanhães, MG, 2004. (a) estação chuvosa, (b) estação seca.

O curso d'água da sub-bacia 4 é interrompido pela estrada e embora ela possua um dispositivo de drenagem da água, este não foi suficiente para suportar a vazão da nascente durante a estação de chuva, inundando a estrada (Figura 9). Esse fluxo excessivo de água pode causar o empobrecimento do solo da bacia pela lixiviação de nutrientes, matéria orgânica e microfauna, resultando em perda de solo, água e nutrientes, além de originar processos de erosão e assoreamento de cursos d'água a jusante, que, por fim, repercutirão na vazão da Cachoeira das Pombas.

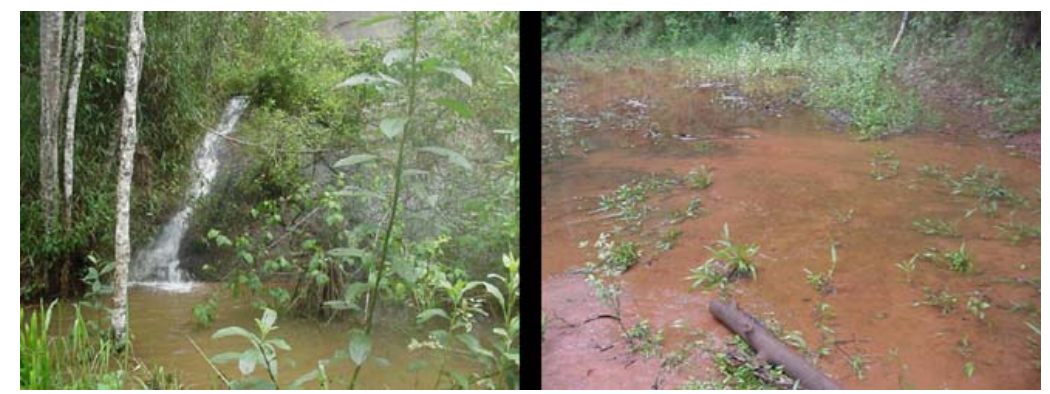

Figura 9. Inundação da estrada por água produzida pela nascente 4, bacia hidrográfica da Cachoeira das Pombas, Guanhães, MG, 2004.

Ao percorrer a bacia hidrográfica, também foram observados vários desmoronamentos de taludes, principalmente na estação chuvosa. Alguns deles chegavam a bloquear totalmente o acesso às estradas (Figura 10). Essas consequências, além de exigirem soluções de alto custo para corrigi-las, trazem danos aos mananciais hídricos pelo assoreamento das nascentes e cursos d'água e pela elevação do nível de turbidez das águas nas áreas adjacentes às estradas. De acordo com Arruda (1997), esses problemas são consequentes da ausência de padrões técnicos construtivos, deficiência do sistema de drenagem (ausência de dispositivos de drenagem superficial, profunda e de transposição de taludes), falta de suporte da camada de rolamento e do subleito (superfície da estrada muito defeituosa) e exposição do horizonte C.

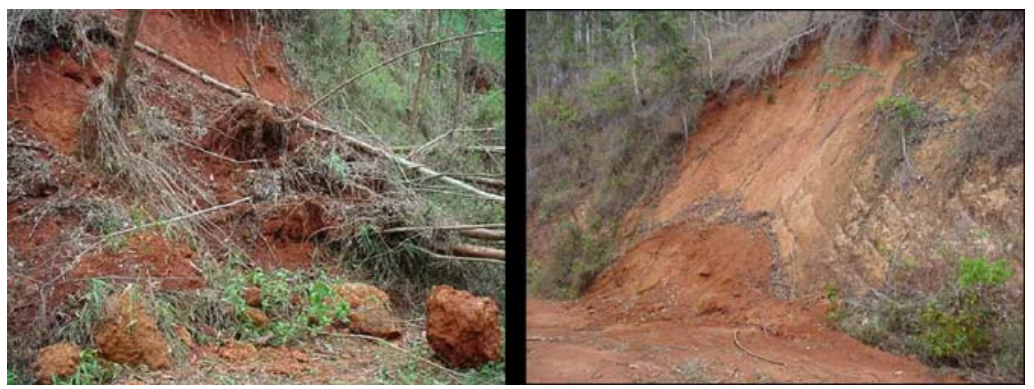

Figura 10. Desmoronamento de taludes na bacia hidrográfica da Cachoeira das Pombas, Guanhães, MG, 2004. 
As represas A e B (Figuras 11, 12) são as mais próximas da Cachoeira das Pombas. Estão diretamente conectadas e recebem toda a água produzida pela bacia hidrográfica direcionando-a para a Cachoeira das Pombas.

Como já esperado, a coloração da água nessas represas entre as estações de chuva e seca, reflete os impactos a montante. Nas chuvas, a água alcança a foz da bacia, ainda com o aspecto barrento como identificado nas áreas a montante. Nota-se um acúmulo de sedimentos em algumas partes da represa $\mathrm{B}$, provocando seu assoreamento.
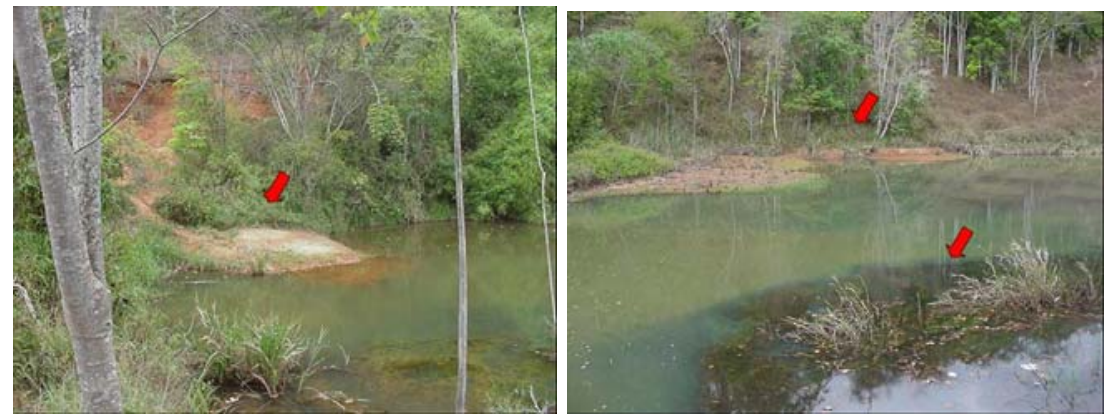

Figura 11. Focos de assoreamento na represa B durante a estação seca, Cachoeira das Pombas, Guanhães, MG, 2004.

Embora não tenha sido mensurado, observou-se uma nítida alteração, não somente da cor, mas também da turbidez da água da bacia em estudo (Figura 12). Essas alterações estão relacionadas à presença de partículas em suspensão nos corpos d'água, o que pode gerar uma considerável redução na quantidade de luz penetrada, com consequente diminuição da produtividade global do ecossistema aquático e com implicações sobre o seu conjunto de organismos.

Observa-se na Figura 13, grande variação na vazão entre as estações seca e chuvosa. Na estação seca (Figura 13b), a vazão foi de $0,34 \mathrm{~L} / \mathrm{s}$ enquanto que na estação chuvosa (Figura 13a) a vazão obtida foi de 6,10 L/s. Segundo depoimentos de moradores da região, a Cachoeira das Pombas possuía um volume de água maior que o atual, no entanto não existe um histórico da vazão da bacia registrado.

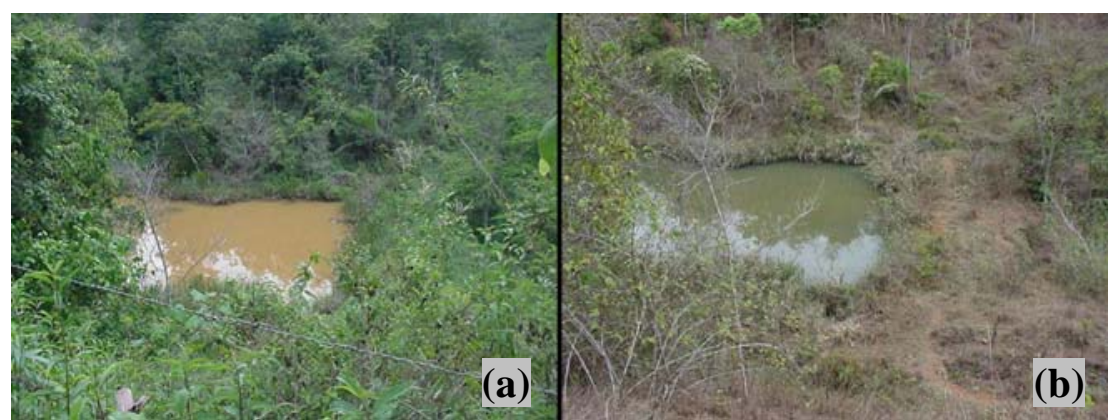

Figura 12. Aspecto da água da represa A, bacia hidrográfica da Cachoeira das Pombas, Guanhães, MG, 2004. (a) estação chuvosa, (b) estação de estiagem. 


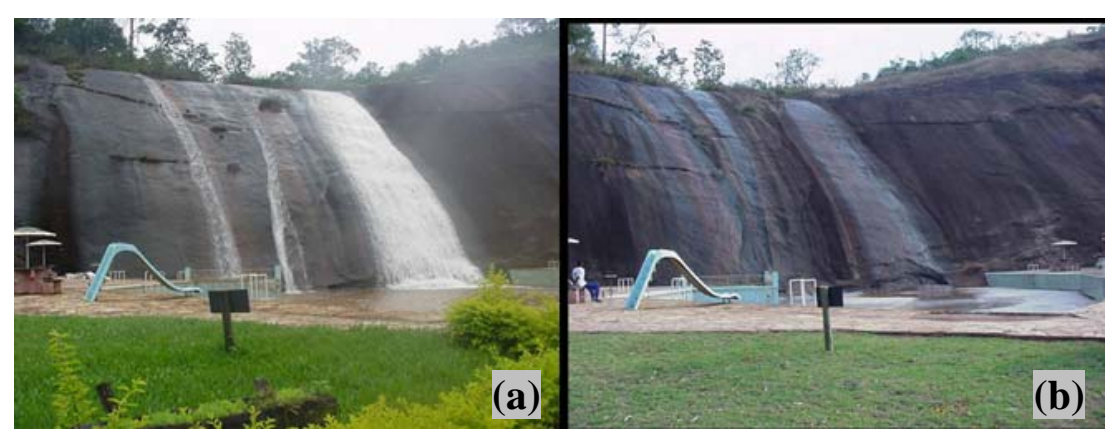

Figura 13. Cachoeira das Pombas, Guanhães, MG, 2004. (a) estação chuvosa e (b) estação seca.

\section{CONCLUSÕES}

Nas condições atuais analisadas na bacia hidrográfica, pode-se concluir que o estado de conservação hídrico e ambiental indica necessidade de integração dos recursos naturais por meio de um manejo integrado. Das seis nascentes caracterizadas, cinco são do tipo encosta e uma do tipo difusa. A verificação do estado de conservação permitiu concluir que das seis nascentes, três encontram-se preservadas, duas degradadas e uma perturbada. A vazão dos cursos d'água apresentou-se desregularizada, durante o período avaliado, com grandes valores na estação chuvosa e posterior redução na estiagem. Isso evidencia a necessidade urgente da realização de práticas conservacionistas de solo e água, assim como o monitoramento hidrológico. Dessa forma, torna-se imprescindível que se faça um planejamento em relação ao uso da terra e que seja embasado no conhecimento científico dos recursos existentes na bacia hidrográfica, de suas estruturas e interdependências.

\section{AGRADECIMENTOS}

À CENIBRA S.A., por todo apoio, fornecimento de dados e informações essenciais para este trabalho e ao CNPq pela concessão da bolsa durante parte do período de estudos.

\section{REFERÊNCIAS}

ARRUDA, P. R. R. Uma contribuição ao estudo ambiental da bacia hidrográfica do Ribeirão São Bartolomeu, Viçosa, MG. 1997, 108f. Dissertação (Mestrado em Ciências Florestais) - UFV, Viçosa-MG, 1997.

BURLA, E. R. Mecanização de atividades silviculturais em relevo ondulado. Belo Oriente: Cenibra, 2001. 144p.

CELULOSE NIPO-BRASILEIRA - CENIBRA. Estudo florístico, fitossociológico e paramétrico das áreas de reserva legal e de preservação permanente da Cenibra. Projeto Cachoeira das Pombas, Região de Guanhães. Belo Oriente: 2003. 143p. (Relatório).

FARAH, M. F. S.; BARBOZA, H. B. Novas experiências de gestão pública e cidadania. Rio de Janeiro: FGV, 2000. 296 p. (Coleção FGV Prática). 
FUNDAÇÃO S.O.S MATA ATLÂNTICA. INSTITUTO NACIONAL DE PESQUISAS ESPACIAIS/ INSTITUTO SÓCIO AMBIENTAL - SOS MATA ATLÂNTICA/ INPE/ ISA. Atlas da evolução dos remanescentes florestais e ecossistemas associados no domínio da Mata Atlântica. São Paulo: Fundação S.O.S. Mata Atlântica, 1998. 54p. (Relatório Nacional).

GONÇALVES, J. L. M. Conservação do solo. In: GONÇALVES, J. L. M.; STAPE, J. L. (ed.). Conservação e cultivo de solos para plantações florestais. Piracicaba: IPEF, 2002. p. 47-129.

INSTITUTO BRASILEIRO DE GEOGRAFIA E ESTATÍSTICA - IBGE. Recursos naturais e meio ambiente: uma visão do Brasil. Rio de Janeiro, 1993. 154p.

LIMA, W. P. Indicadores hidrológicos do manejo sustentável de plantações de eucalipto. In: IUFRO CONFERENCE ON SILVICULTURE AND IMPROVEMENT OF EUCALYPT. Proceedings... Colombo: Embrapa - CNPF, 1997. p. 13-29.

LIMA, W. P.; ZAKIA, M. J. B.; CÂMARA, C. D. Implicações da colheita florestal e do preparo do solo na erosão e assoreamento de bacias hidrográficas. In: GONÇALVES, J. L. M.; STAPE, J. L. (Ed.). Conservação e cultivo de solos para plantações florestais. Piracicaba: IPEF, 2002. p. 373-391.

MATTEUCCI, M. B. A.; COSTA, B. S.; GRASSI, G.; BRAGA, G. C.; MOTA, V.G.O.; FERNANDES, P. S. S. Avaliação ambiental da bacia do Meia Ponte: tributários da bacia dentro da cidade de Goiânia - GO. In: SIMPÓSIO BRASILEIRO DE RECURSOS HÍDRICOS E $8^{\circ}$ SIMPÓSIO DE HIDRÁULICA E RECURSOS HÍDRICOS DOS PAÍSES DE LÍGUA OFICIAL PORTUGUESA, 17., 25 - 29 nov. São Paulo. Proceedings... São Paulo: ABRH, 2007. 1 CD-ROOM.

MOSCA, A. A. O. Caracterização hidrológica de duas microbacias visando à identificação de indicadores hidrológicos para o monitoramento ambiental do manejo de florestas plantadas. 2003. 96f. Dissertação (Mestrado em Ciências Florestais) - ESALQ/USP, Piracicaba, 2003.

PINTO, L. V. A.; BOTELHO, S. A.; DAVIDE, A. C.; FERREIRA, E. Estudos das nascentes da bacia hidrográfica do Ribeirão Santa Cruz, Lavras, MG. Scientia Florestalis, n.65, p.1-10, 2004.

PIRES, J. S. R.; SANTOS, J. E.; DEL PRETTE, M. E. A utilização do conceito bacia hidrográfica para a conservação dos recursos naturais. In: SCHIAVETTI, A.; CAMARGO, A. F. M. (Ed.). Conceitos de bacias hidrográficas: Teorias e Aplicações. Ilhéus: Editus, 2002. p. 17-35.

SANTANA, J. R. O.; SOUSA, R. T. C.; MATTEUCCI, M. B. A. Diagnóstico ambiental das áreas de preservação permanente (app) do córrego Capim Puba, Goiânia, Goiás, Brasil. In: SIMPÓSIO BRASILEIRO DE RECURSOS HÍDRICOS E $8^{\circ}$ SIMPÓSIO DE HIDRÁULICA E RECURSOS HÍDRICOS DOS PAÍSES DE LÍGUA OFICIAL PORTUGUESA, 17., 25 - 29 nov. São Paulo. Proceedings... São Paulo: ABRH, 2007. 1 CD-ROOM. 
SOUZA, M. J. H.; RIBEIRO, A.; LEITE, H. G.; LEITE, F. P.; MINUZZI, R. B. Relação entre disponibilidade hídrica e produtividade do eucalipto em diferentes idades, em Guanhães, Minas Gerais. Revista Brasileira de Engenharia Agrícola e Ambiental, v. 10, n. 3, p. 629-638, 2006.

TONELLO, K. C.; DIAS, H. C. T.; SOUZA, A. L. de; RIBEIRO, C. A. A. S.; LEITE, F. P. Morfometria da bacia hidrográfica da Cachoeira das Pombas, Guanhães-MG. Revista Árvore, v. 30, n. 5, p. 849-857, 2006.

VALCARCEL, R. Balanço hídrico no ecossistema florestal e sua importância conservacionista na região ocidental dos Andes Venezuelanos. In: SEMINÁRIO SOBRE ATUALIDADES E PERSPECTIVAS FLORESTAIS, 11., 1984, Curitiba. Anais... Curitiba: Embrapa, 1984. 142p. 